\title{
Effect of homopolymer poly(vinyl acetate) on compatibility and mechanical properties of poly(propylene carbonate)/poly(lactic acid) blends
}

\author{
J. Gao, H. Bai, Q. Zhang, Y. Gao, L. Chen, Q. Fu* \\ Department of Polymer Science and Materials, Sichuan University, State Key Laboratory of Polymer Materials \\ Engineering, 610065 Chengdu, P.R. China
}

Received 18 March 2012; accepted in revised form 17 May 2012

\begin{abstract}
A small amount of homopolymer poly(vinyl acetate) (PVAc) is used to compatibilize the biodegradable blends of poly(propylene carbonate) (PPC) and poly(lactic acid) (PLA). Scanning electron microscopy (SEM) and differential scanning calorimetry (DSC) results show that PVAc is selectively localized in the PLA phase and at the interface between PPC and PLA phases. As a result, these interface-localized PVAc layers act as not only a compatibilizer to improve the phase dispersion significantly but also a bridge to increase the interfacial adhesion between PPC and PLA phases dramatically. Both of them are believed to be responsible for the enhancement in mechanical properties. This work provides a simple avenue to fabricate eco-friendly PPC/PLA blends with high performance, and in some cases, reducing the demand for petroleumbased plastics such as polypropylene.
\end{abstract}

Keywords: mechanical properties, poly(propylene carbonate), poly(lactic acid), poly(vinyl acetate), compatibility

\section{Introduction}

Recently, much effort has been devoted to developing biodegradable and renewable resource-derived polymers because of the worldwide environment concerns and sustainability issues resulted from petroleum-based polymers. Poly(propylene carbonate) (PPC), derived from carbon dioxide $\left(\mathrm{CO}_{2}\right)$ and propylene oxide, is one such polymer attracting great research attention. The utilization of $\mathrm{CO}_{2}$ as one of the synthetic monomers can largely reduce the dependence on petroleum resources and the emission of $\mathrm{CO}_{2}$ contributing to the greenhouse effect [1-4]. Generally, PPC exhibits excellent tensile toughness and transparency. However, its inferior tensile strength and low glass transition temperature $\left(T_{\mathrm{g}}\right.$, around $35^{\circ} \mathrm{C}$ ) are the major drawbacks to prevent it from widely practical applications $[5,6]$. Therefore, melt blending of PPC with various biodegradable polymers, such as poly(3-hydroxybutyrate) (PHB) [7], poly(butylenes succinate) (PBS) [8], poly(ethylene-co-vinyl alcohol) (EVOH) [9], and starch [10], has drawn much attention to obtain PPC materials with good biodegradability and improved properties. Poly(lactic acid) (PLA) is another promising biodegradable polymer derived from renewable resources (e.g., corn, wheat, or rice). It exhibits a potential as an effective reinforcing agent for PPC due to its high strength and stiffness $[11,12]$. On the other hand, its inherent brittleness can be simultaneously improved by the flexible PPC as a toughening agent [13].

It is well-known that the mechanical properties of a polymer blend are greatly dependent on its phase morphology and interfacial adhesion [14-16]. How-

\footnotetext{
${ }^{*}$ Corresponding author, e-mail: qiangfu@scu.edu.cn
}

(c) BME-PT 
ever, most polymer pairs are incompatible thermodynamically. The coarse phase morphology and poor interfacial adhesion often give rise to unfavorable property combinations in the blends [17]. Although PPC and PLA have been reported to be partially compatible, compatibilization is also required to further improve its phase morphology and then endow the blend with desirable properties [18]. The introduction of well-defined block or graft copolymers into immiscible polymer blends is the most popular compatibilization strategy $[19,20]$. Unfortunately, to the best of our knowledge, no commercially available block copolymer can be used as an effective compatibilizer for PPC/PLA blends at this time. Moreover, the in situ formation of graft copolymers by reactive blending is often not straightforward. In very limited investigations, another strategy, i.e. adding random copolymer or homopolymer, has been successfully used to improve the compatibilization of incompatible blends [21, 22]. In these cases, the selective localization of compatibilizer at the interface between the blend components is of vital importance to manipulate interface properties. Selective localization of a third component in incompatible binary blends is mainly attributed to the difference in the affinity between the third component and the blend components [23, 24]. Generally, the effective compatibilizer (e.g. well-designed block copolymer) prefers to locate at the phase interface as a result of the similar affinity to each of the matrix components. In previous works, poly(vinyl acetate) (PVAc) has been demonstrated to be compatible with both PPC and PLA $[25,26]$. Therefore, in this contribution, a small amount of PVAc (10 wt\%) was introduced into PPC/PLA blends. It is expected that PVAc could be mainly located at the phase interface as a compatibilizer to reduce interfacial tension and suppress coalescence of discrete domains, and thus leading to a significant improvement in mechanical performance of the PPC/PLA blends.

\section{Experimental}

\subsection{Materials}

Maleic anhydride end-capped poly (propylene carbonate) (PPC) was supplied by Changchun Institute of Applied Chemistry, Chinese Academy of Science. Its weight-average molecular weight $\left(M_{\mathrm{w}}\right)$ was $2.48 \cdot 10^{5} \mathrm{~g} / \mathrm{mol}$ and $M_{\mathrm{w}} / M_{\mathrm{n}}$ was 3.2. Poly(lactic acid) (PLA), with $M_{\mathrm{w}}=1.59 \cdot 10^{5} \mathrm{~g} / \mathrm{mol}$ and $M_{\mathrm{w}} / M_{\mathrm{n}}=$ 2.75, was purchased from Haizheng Biomaterial Co. (Zhejiang, China). The $M_{\mathrm{w}}$ of poly(vinyl acetate) (PVAc) used in this work was about $1.7 \cdot 10^{5} \mathrm{~g} / \mathrm{mol}$, and was provided by Acros organics USA. The chemical structures of PPC, PLA and PVAc are given in Figure 1.

\subsection{Preparation of blends}

PPC/PLA blends with and without PVAc were prepared by direct melt compounding in a HAAKE torque rheometer (Thermo Fisher Scientific, USA) at $50 \mathrm{rpm}$ for $7 \mathrm{~min}$. And the temperature was set at $150^{\circ} \mathrm{C}$, which ensured that PPC and PVAc will not decompose. The content of PVAc was set as $10 \mathrm{wt} \%$ in the ternary blends. Specimens for tensile and dynamic mechanical measurements were compression molded at $150^{\circ} \mathrm{C}$ under a pressure of $10 \mathrm{MPa}$ and then cut into dumb-bell shaped sheets (about 1 $\mathrm{mm}$ in thickness). Before being used, all materials were dried in a vacuum oven at $45^{\circ} \mathrm{C}$ for $24 \mathrm{~h}$.

\subsection{Characterization}

Dynamic mechanical properties (DMA) were conducted using a TA Instruments Q800 dynamic mechanical analyzer (USA) in a film-tension mode at a frequency of $1 \mathrm{~Hz}$. The temperature ranged from -10 to $90^{\circ} \mathrm{C}$ at a heating rate of $3^{\circ} \mathrm{C} / \mathrm{min}$.

The tensile-fractured surfaces of the specimens were characterized by using an Inspect $F$ fieldemission SEM (FEI Company, USA) with 5-20 kV accelerating voltage. For the observation of phase morphologies, the specimens were first cryogenically fractured in liquid nitrogen. Then the PPC

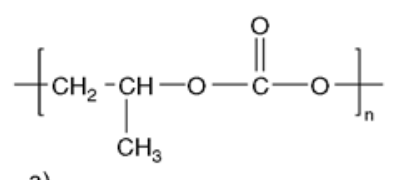

a)

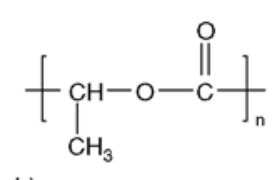

b)

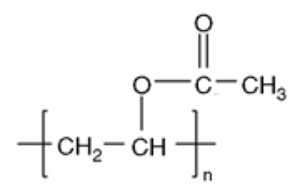

c)

Figure 1. Chemical structures of (a) PPC, (b) PLA, and (c) PVAc 
phase and PVAc were etched away in a mixed solution of anhydrous ethanol and acetone $(1: 1, \mathrm{v} / \mathrm{v})$ at room temperature for $6 \mathrm{~h}$. To determine the dispersion state of PVAc in the blends, anhydrous methanol was also used as an etching agent to selectively dissolve the PVAc phase at room temperature for $12 \mathrm{~h}$. Before SEM characterization, both the etched surfaces and tensile-fractured surfaces were coated with a thin layer of gold.

A Netzsch DSC 204 Phoenix (Germany) was used to investigate the effect of PVAc on the crystallization behavior of PPC/PLA blends. The specimens (about $5 \mathrm{mg}$ ) were first heated from room temperature to $190^{\circ} \mathrm{C}$ rapidly and then kept at this temperature for $5 \mathrm{~min}$ to eliminate the thermal history. The cooling curves were recorded from 190 to $0^{\circ} \mathrm{C}$ at a cooling rate of $2^{\circ} \mathrm{C} / \mathrm{min}$. The values of crystallization temperature $\left(T_{\mathrm{c}}\right)$ could be obtained from the cooling curves. All measurements were carried out under a nitrogen atmosphere.

All FTIR spectra were recorded at $4 \mathrm{~cm}^{-1}$ resolution using a Thermo Scientific Nicolet 6700 spectrometer equipped with Smart iTR attenuated total reflection (ATR) accessory. Tensile testing was performed using an Instron 4302 universal tensile testing machine (USA) with a crosshead speed of $10 \mathrm{~mm} / \mathrm{min}$ at $23^{\circ} \mathrm{C}$. The results reported were the average from at least five specimens for each testing.

\section{Results and discussion}

\subsection{Compatibility and phase morphology}

The compatibility of PPC/PLA blends was evaluated by DMA. Figure 2 shows the plots of dynamic loss modulus versus temperature for PPC, PLA, and 50PPC/50PLA blend with and without PVAc. The glass transition temperature $\left(T_{\mathrm{g}}\right)$ can be obtained from the peak in the plots. Neat PPC and PLA exhibit the glass transition at 27.1 and $55.0^{\circ} \mathrm{C}$, respectively.

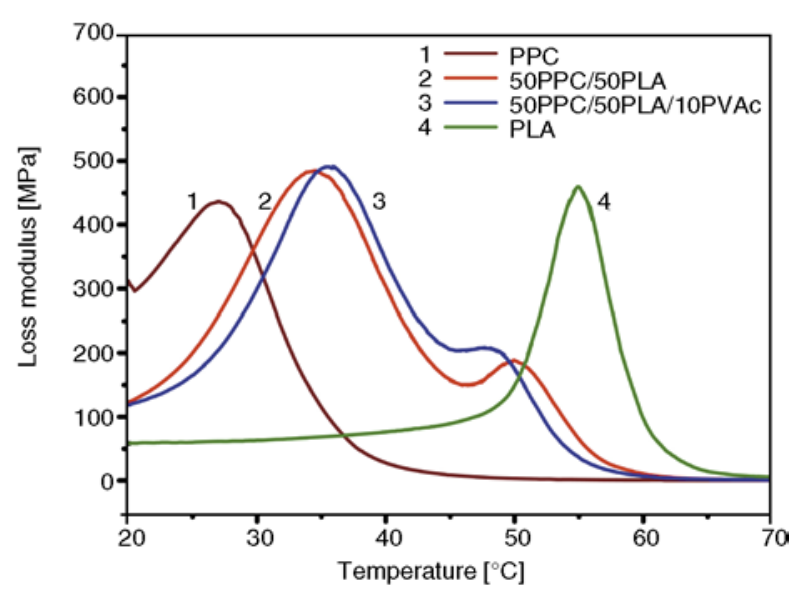

Figure 2. Loss modulus of PPC, PLA, and 50PPC/50PLA blend with and without PVAc as a function of temperature

As previously reported by Ma et al. [18], the $T_{\mathrm{g}}$ of both PPC and PLA shifts significantly towards each other in the blend, suggesting that PPC and PLA are partially compatible. More importantly, adding a small amount of PVAc (10 wt $\%)$ into the blend gives rise to not only a clearly increased $T_{\mathrm{g}}$ of PPC (from 34.5 to $36.0^{\circ} \mathrm{C}$ ) but also a decreased $T_{\mathrm{g}}$ of PLA (from 50.0 to $47.7^{\circ} \mathrm{C}$ ). Similar results have also been obtained from 30PPC/70PLA and 70PPC/ 30PLA blends with and without PVAc, as shown in Table 1. Evidently, the difference in the values of $T_{\mathrm{g}}$ between PPC and PLA decreases clearly with the introduction of PVAc, indicating that PVAc can act as a good compatibilizer for the PPC/PLA blends. The enhanced compatibility between PPC and PLA by adding PVAc can be further proved from the changes in the phase morphology of PPC/PLA blends with and without PVAc, as presented in Figure 3. It is obvious that 70PPC/30PLA blend exhibits a typical sea-island morphology, in which PLA domains are dispersed in the PPC matrix (Figure 3a), while 50PPC/50PLA blend exhibits a co-continu-

Table 1. Glass transition temperatures $\left(T_{\mathrm{g}}\right)$ and Mechanical Properties of PPC/PLA blends with and without PVAc

\begin{tabular}{|l|c|c|c|c|c|}
\hline \multicolumn{1}{|c|}{ Samples } & $\begin{array}{c}\mathbf{T}_{\mathbf{g}, \mathbf{P P C}} \\
{\left[{ }^{\circ} \mathbf{C}\right]}\end{array}$ & $\begin{array}{c}\mathbf{T}_{\mathbf{g}, \mathbf{P L A}} \\
{\left[{ }^{\circ} \mathbf{C}\right]}\end{array}$ & $\begin{array}{c}\text { Tensile strength } \\
{[\mathbf{M P a}]}\end{array}$ & $\begin{array}{c}\text { Young's modulus } \\
{[\mathbf{M P a}]}\end{array}$ & $\begin{array}{c}\text { Elongation at break } \\
{[\% \mathbf{m}]}\end{array}$ \\
\hline PPC & 27.1 & - & $6.2 \pm 0.5$ & $121 \pm 40$ & $988 \pm 40$ \\
\hline 70PPC/30PLA & 32.2 & ${ }^{\text {a) }}$ & $17.3 \pm 1.5$ & $1104 \pm 80$ & $118 \pm 35$ \\
\hline 70PPC/30PLA/10PVAc & 34.0 & ${ }^{\text {a) }}$ & $28.5 \pm 3.0$ & $1434 \pm 150$ & $187 \pm 60$ \\
\hline 50PPC/50PLA & 34.5 & 50.0 & $28.3 \pm 1.0$ & $1588 \pm 80$ & $6 \pm 10$ \\
\hline 50PPC/50PLA/10PVAc & 36.0 & 47.7 & $40.2 \pm 2.5$ & $1787 \pm 100$ & $65 \pm 10$ \\
\hline 30PPC/70PLA & 37.1 & 53.3 & $45.6 \pm 3.2$ & $1965 \pm 40$ & $28 \pm 11$ \\
\hline 30PPC/70PLA/10PVAc & 37.7 & 52.0 & $50.7 \pm 1.5$ & $1960 \pm 80$ & $40 \pm 5$ \\
\hline PLA & - & 55.0 & $59.8 \pm 2.0$ & $2164 \pm 85$ & $4 \pm 1$ \\
\hline
\end{tabular}

a) can not be determined from the loss modulus plots 

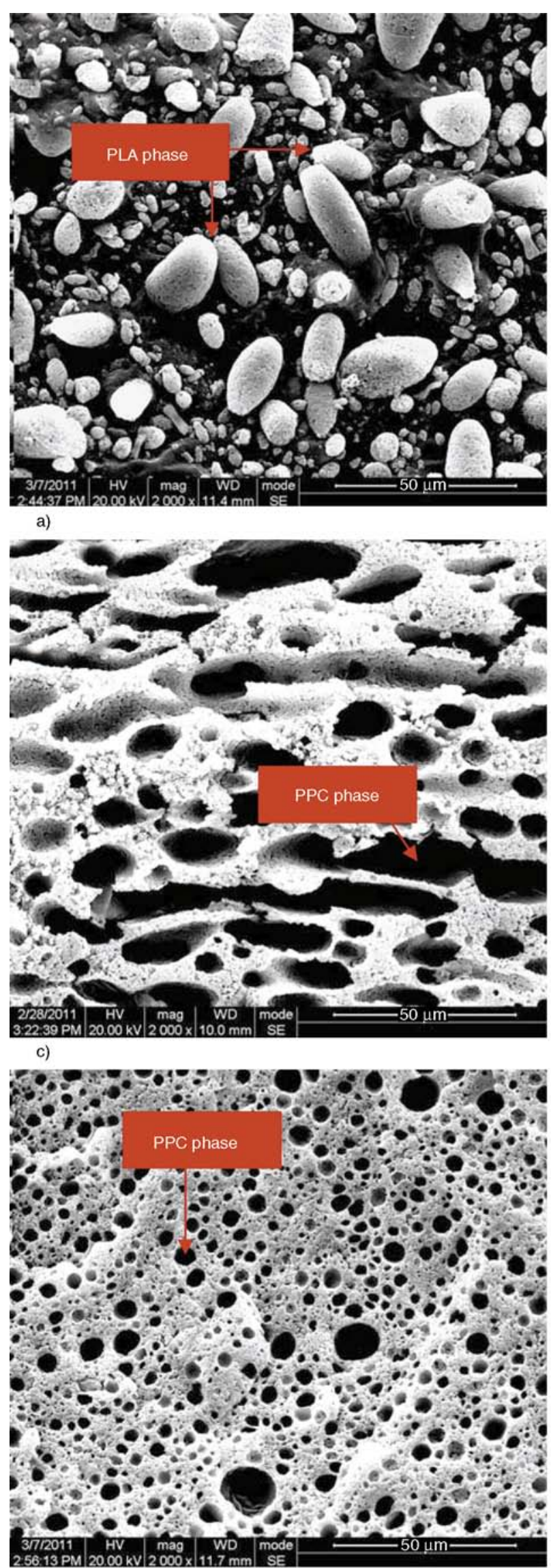

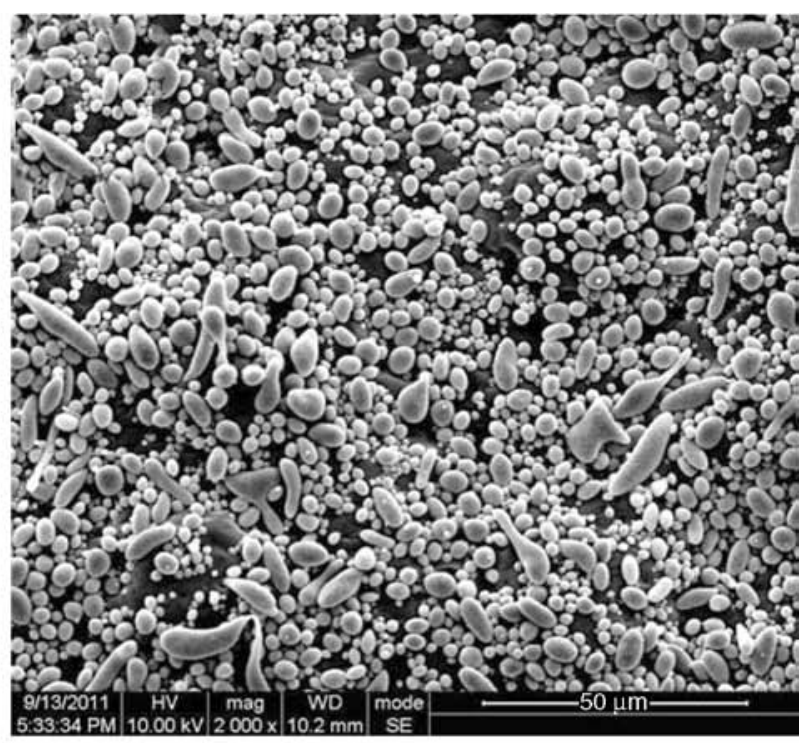

b)
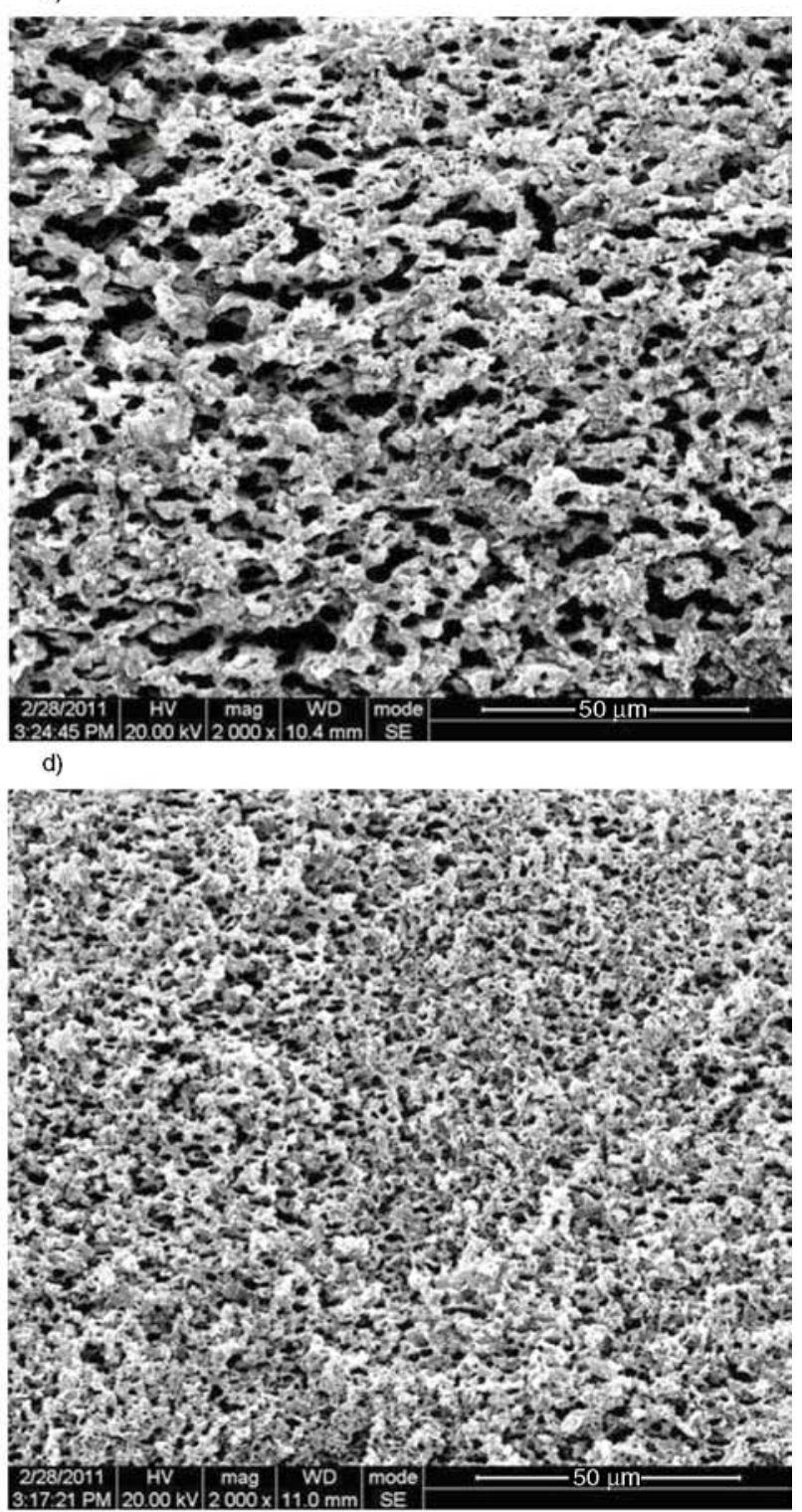

Figure 3. SEM micrographs of PPC/PLA blends with and without PVAc: (a) 70 PPC/30PLA, (b) 70PPC/30PLA/10PVAc, (c) 50PPC/50PLA, (d) 50PPC/50PLA/10PVAc, (e) 30PPC/70PLA, and (f) 30PPC/70PLA/10PVAc 
ous morphology (Figure 3c). With increasing PLA content up to $70 \mathrm{wt} \%$, however, the primarily continuous PPC phase is gradually transformed into dispersed droplets, followed by more and more dispersed PLA droplets in the PPC matrix coalesce together, forming another typical sea-island morphology (Figure 3e). Very interestingly, with the addition of PVAc, a much finer and more uniform phase structure is presented, which is similar to the results of introducing well-designed block copolymers into incompatible polymer blends [27]. For the compatibilized blend, the dispersed phase in the SEM micrographs is attributed to PPC-rich phase because the PVAc also can be etched away in the

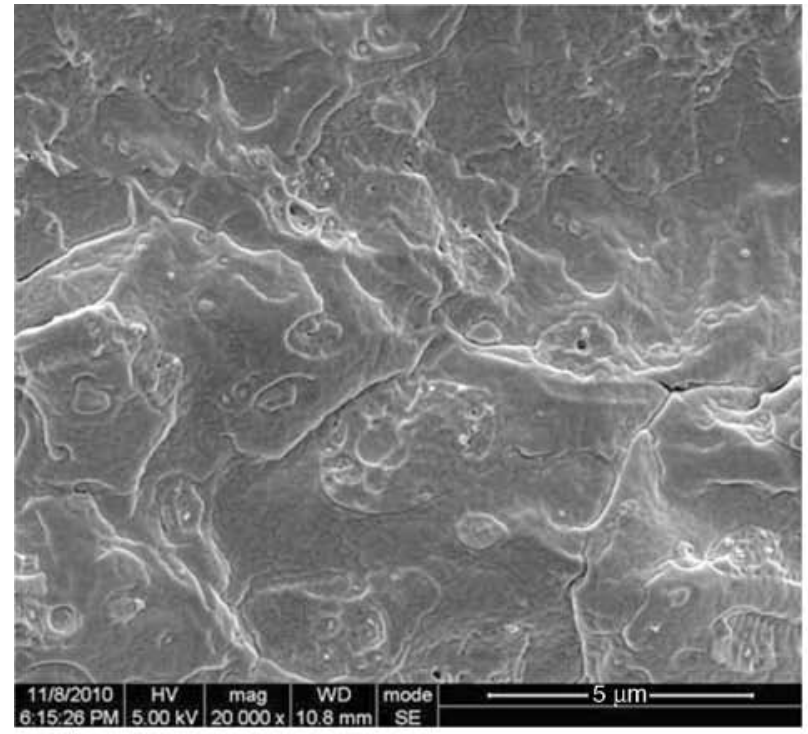

a)

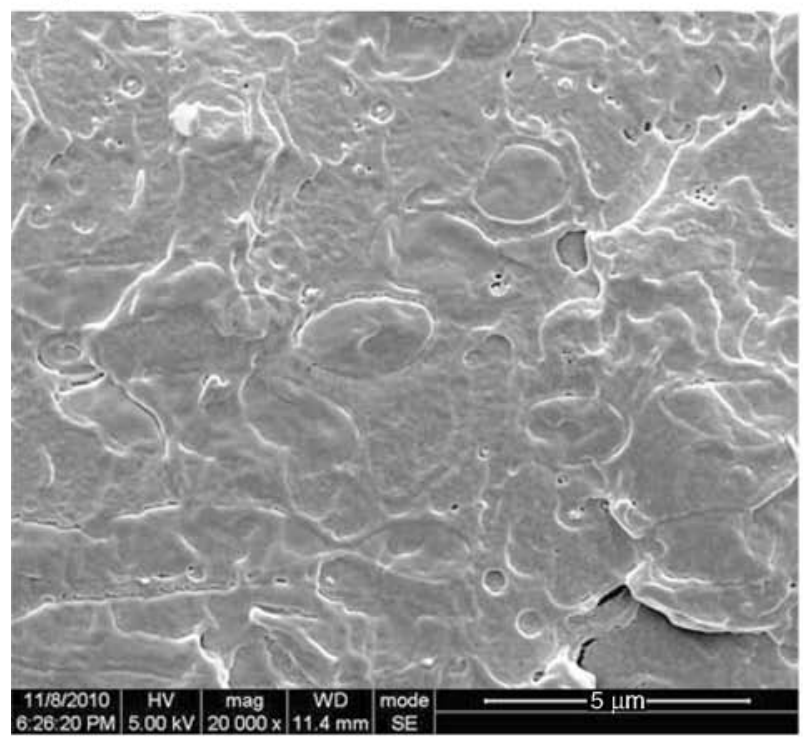

c) mixed solution. For example, the size of dispersed PPC domains in the 30PPC/70PLA blend ranges from 5 to $15 \mu \mathrm{m}$, whereas in the 30PPC/70PLA/ 10PVAc PPC-rich dispersed phase is significantly decreased to less than $5 \mu \mathrm{m}$ (Figure $3 \mathrm{e}$ and $3 \mathrm{f}$ ). This further demonstrates that PVAc can improve the compatibility between PPC and PLA significantly. The improved compatibility may origin from the selective localization of PVAc in PPC/PLA blends. This assumption is well supported by another morphological observation of the blends as shown in Figure 4. Because it is very difficult to clarify the dispersion state of PVAc in the blends through SEM images of the cryogenically fractured surfaces (Fig-

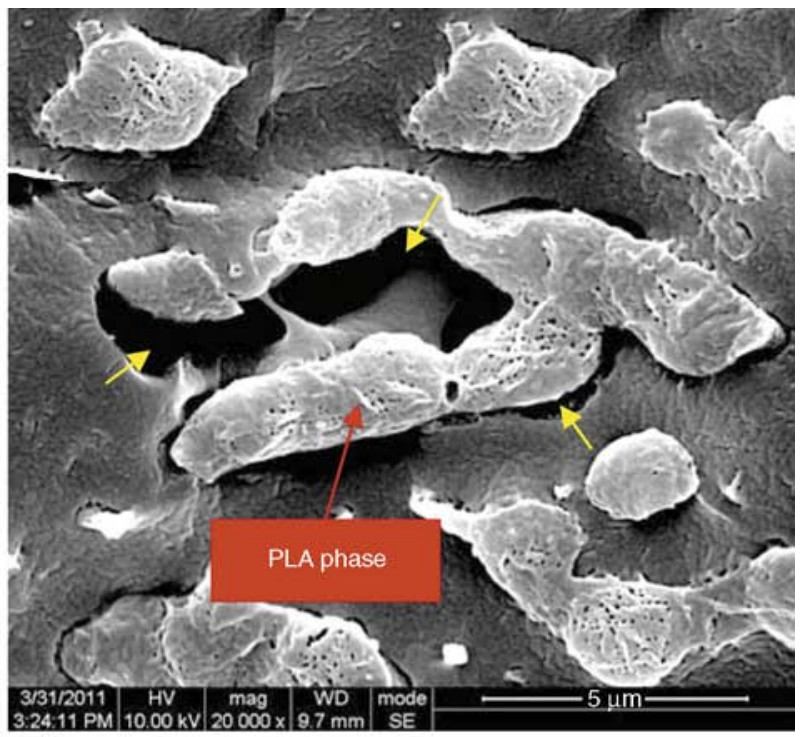

b)

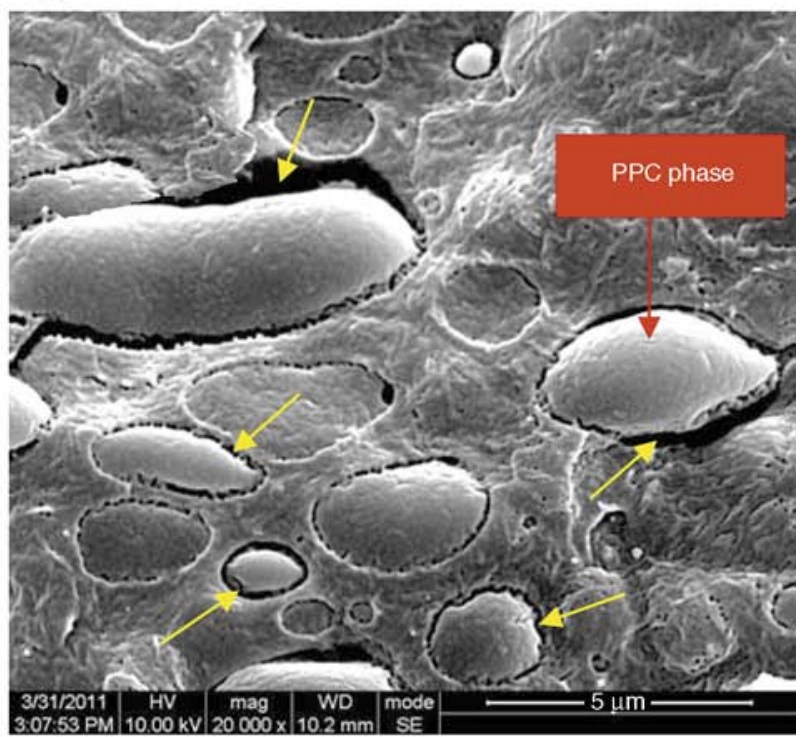

d)

Figure 4. SEM micrographs show the dispersion of PVAc in (a, b) 70PPC/30PLA/10PVAc and (c, d) 30PPC/70PLA/ 10PVAc blends. (a) and (c) are the images of cryogenically fractured surfaces, while (b) and (d) are the subsequently etched surfaces. PVAc was selective dissolved by anhydrous methanol as shown by the arrows. 
ure $4 \mathrm{a}$ and $4 \mathrm{c}$ ), PVAc was selective removed from the blends by anhydrous methanol (both PPC and PLA cannot be dissolved in anhydrous methanol). As shown in Figure $4 \mathrm{~b}$ and $4 \mathrm{~d}$, the dark holes represent the removed PVAc phase. Clearly, PVAc is selectively located at the interface between PPC and PLA phases as highlighted by the arrows. Furthermore, a fraction of PVAc may be dispersed in the PLA phase, evidenced by the existence of some tiny dark holes in the PLA droplets (Figure 4b). This indicates that PVAc may have a higher affinity to PLA than to PPC. In this case, a small amount of the PVAc has a tendency to migrate from the phase interface to the PLA phase during melt blending. The dispersion of PVAc in the PLA phase can also be confirmed by the results of DSC measured crystallization behavior of PPC/PLA blends with and without PVAc. As clearly shown in Figure 5, for 30PPC/70PLA and 50PPC/50PLA blends, no apparent changes in $T_{\mathrm{c}}$ of PLA can be observed compared to neat PLA. Similar result has been found in PPC/ PHB blends, where the crystallization of PHB is independent of the presence of PPC [7]. However, with the addition of PVAc, a significant decrease of $T_{\mathrm{c}}$ appears in both the PLA and PPC/ PLA blends. Because the shift degree of the two $T_{\mathrm{c}}$-s are almost equivalent, the depressed crystallization of PLA in PPC/PLA/PVAc blends should be attributed to the PVAc dispersed in the PLA phase. The strong interaction between PVAc and PLA may play a negative role for the crystallization of PLA by hindering the movement and rearrangement of molecular chains. In particular, the $T_{\mathrm{c}}$ of PLA in 70PPC/30PLA blend is much lower than that in 30PPC/70PLA or 50PPC/

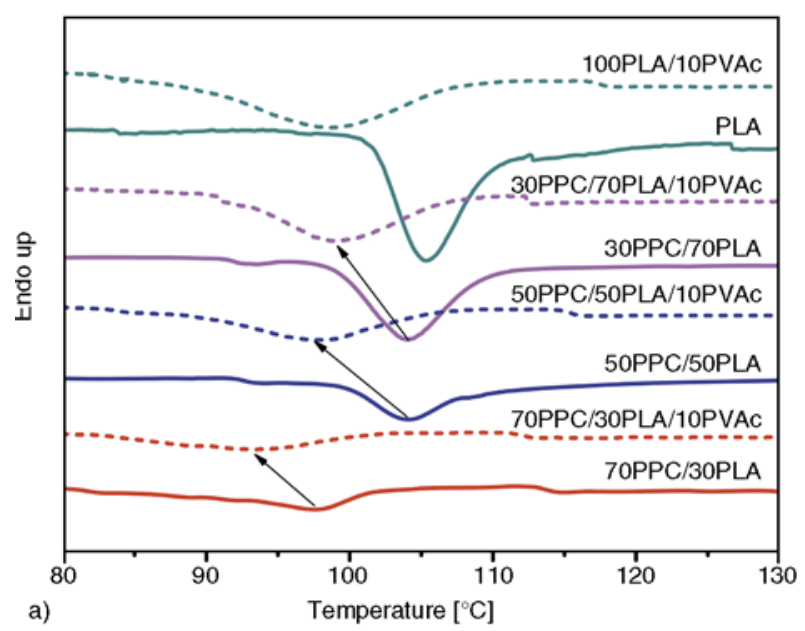

50PLA blend, indicating the confined crystallization of PLA in the case of PPC being a continuous phase (Figure 3e).

\subsection{Molecular mechanisms for the compatibilization}

Due to the similar chemical structures of the three polymers, the possible molecular mechanisms for the interactions between the interface-localized PVAc and the two matrix components (i.e. PPC and PLA) are analyzed with FTIR spectra of PPC, PLA, and their blends with and without PVAc. As shown in Figure 6 , in the $\mathrm{C}=\mathrm{O}$ stretching vibration region, the absorption peak of PLA at $1747 \mathrm{~cm}^{-1}$ shifts significantly towards lower wavenumber with the addition of $50 \mathrm{wt} \%$ PPC due to the specific intermolecular interactions between PPC and PLA, such as $\mathrm{C}=\mathrm{O} \cdots \mathrm{O}=\mathrm{C}$ dipole-dipole interaction [18]. More

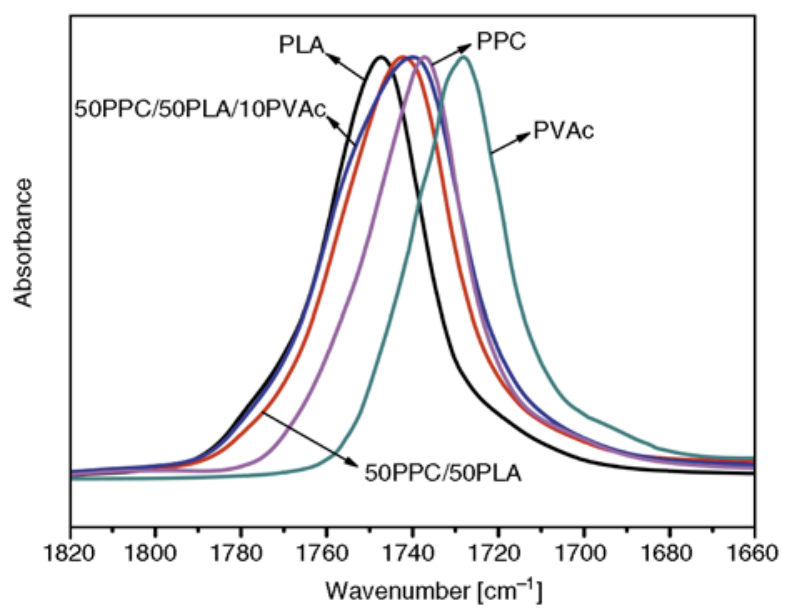

Figure 6. Normalized FTIR spectra of $\mathrm{C}=\mathrm{O}$ stretching bands for PPC, PLA, PVAc and PPC/PLA blends with and without PVAc

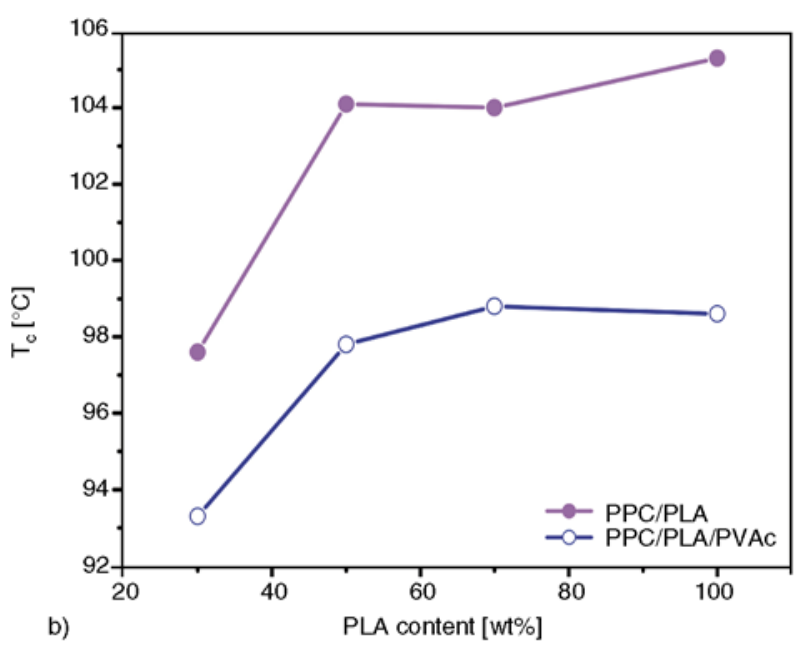

Figure 5. (a) DSC cooling curves of PPC/PLA blends with and without PVAc, and (b) crystallization temperature $\left(T_{\mathrm{c}}\right)$ as a function of PLA content 
importantly, it is interesting to note that the addition of PVAc into the PPC/PLA blend gives rise to not only a peak shifting of the $\mathrm{C}=\mathrm{O}$ stretching band (from 1742 to $1739 \mathrm{~cm}^{-1}$ ) but also an obvious peak broadening, suggesting that PVAc is likely to improve the interaction between PPC and PLA molecules. The potential molecular mechanisms for the enhanced interaction may be the $\mathrm{CH}_{3} \cdots \mathrm{O}=\mathrm{C}$ interaction, as in the case for PHB/PLA/PVAc blends proposed by El-Hadi [28]. To give a direct evidence on the validity of this assumption, the FTIR spectra of neat PPC, PLA, and PPC/PVAc and PLA/PVAc blends were measured. Unfortunately, because the chemical constitution of PVAc is very similar to those of PPC and PLA (Figure 1), both the absorption peaks assigned to the $\mathrm{CH}_{3}$ deformation bands and those corresponding to the $\mathrm{C}=\mathrm{O}$ stretching vibration bands overlap for PPC/ PVAc and PLA/PVAc blends, then the spectra become complicated and it is difficult to reveal the direct interaction according to the changes in peak position and peak shape. Maybe as the literature reported, the interaction between $\mathrm{C}=\mathrm{O}$ groups of PLA and $\mathrm{CH}_{3}$ groups of PVAc is considered to be the main contribution to the compatibility between PLA and PVAc [26]. This type of hydrogen bonding has also been reported to exist in PLLA/PDLA stereocomplex [29]. For PPC/PVAc blends, such weak hydrogen bonding is likely to favor the compatibility due to the fact that $\mathrm{PPC}$ and PLA have similar $\mathrm{C}=\mathrm{O}$ groups in main chains. Because of the delicate difference between the FTIR spectra, the exact molecular mechanisms need further investigation and will be reported in further work.

From above discussion, it is obvious that the compatibility between PPC and PLA is improved dra-

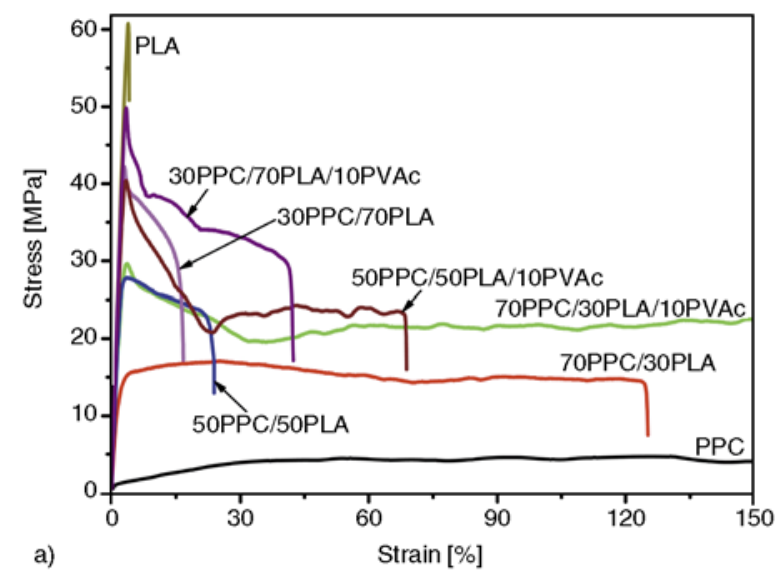

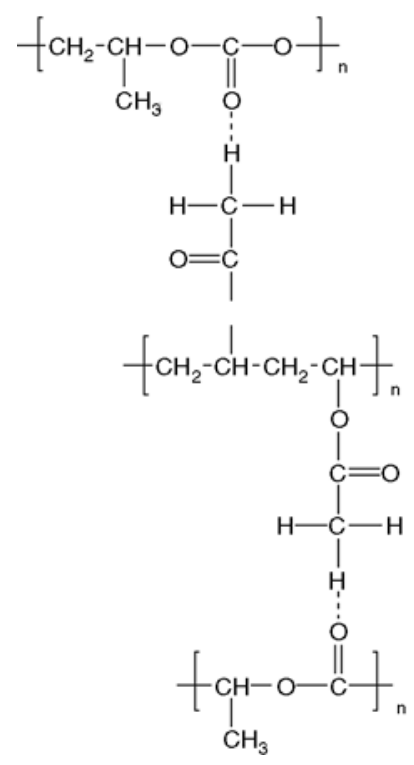

Figure 7. Schematic representation of the possible compatibilizing mechanism of PVAc in PPC/PLA blends

matically upon of PVAc, which is selectively dispersed at the phase interface and in the PLA phase. At the current stage of this study, we give a briefly schematic representation of the possible compatibilizing mechanism of PVAc in the binary blends, as shown in Figure 7. These interface-localized PVAc can act as a compatibilizer to reduce the interfacial tension through specific intermolecular interactions with the two matrix components (i.e. PPC and PLA) and hinder the domains coalescence during blending, thus leading to a much refined phase morphology.

\subsection{Mechanical properties}

As discussed in the introduction, the phase morphology of multiphase polymer blends plays a crucial role in determining their performance. Therefore, with the addition of a small amount of PVAc

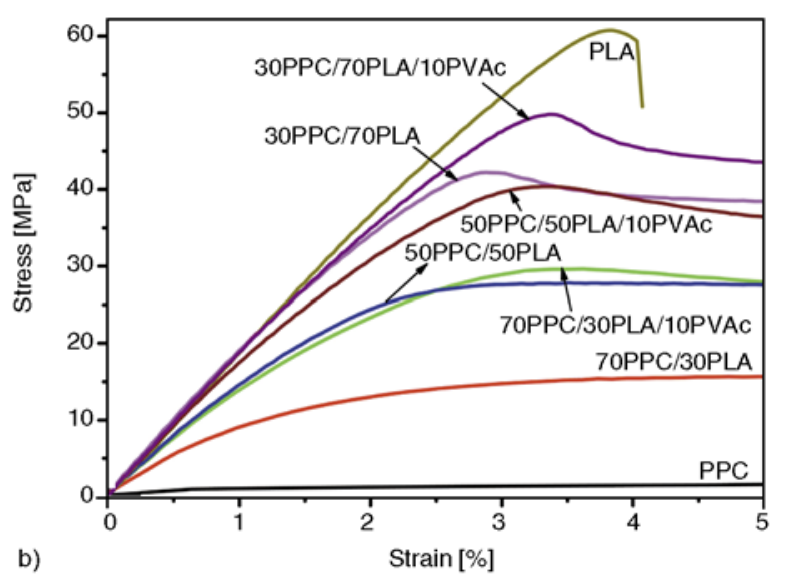

Figure 8. (a) stress-strain curves of of PPC/PLA blends with and without PVAc, and (b) enlarged part of the curves 


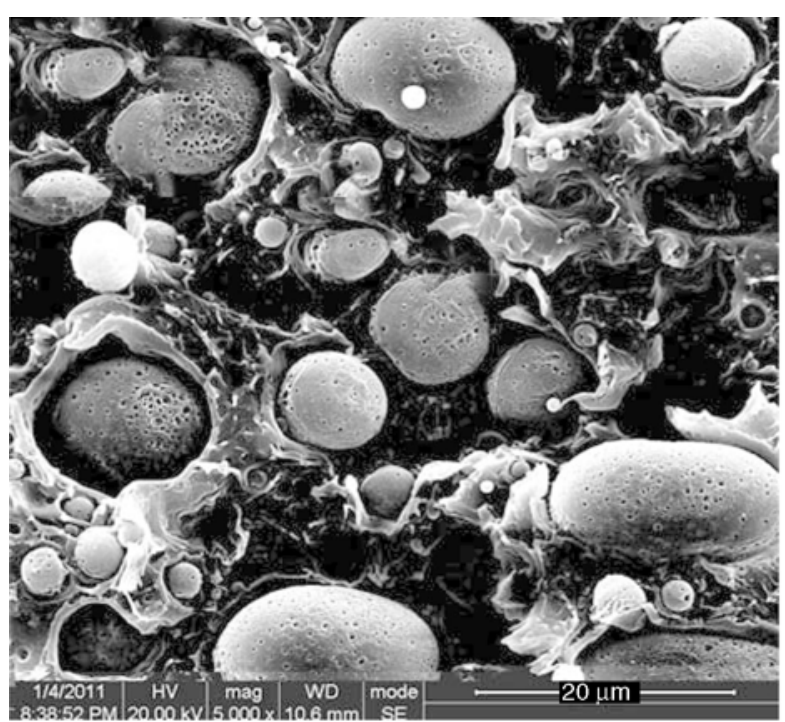

a)
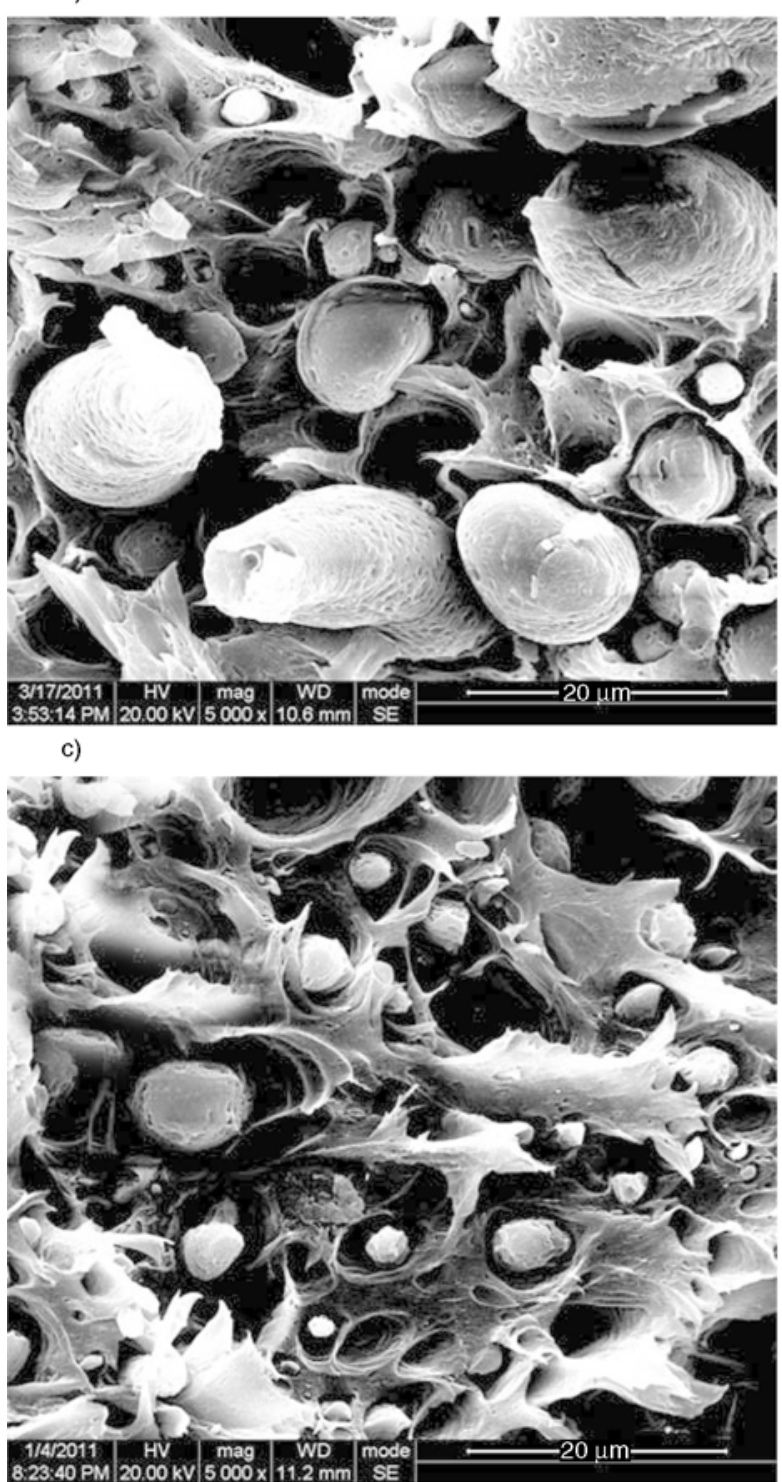

e)

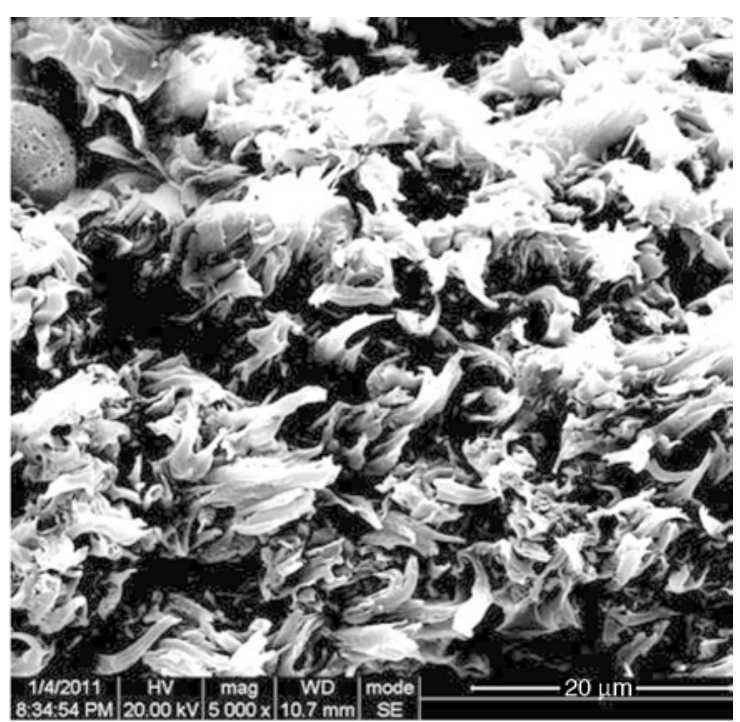

b)
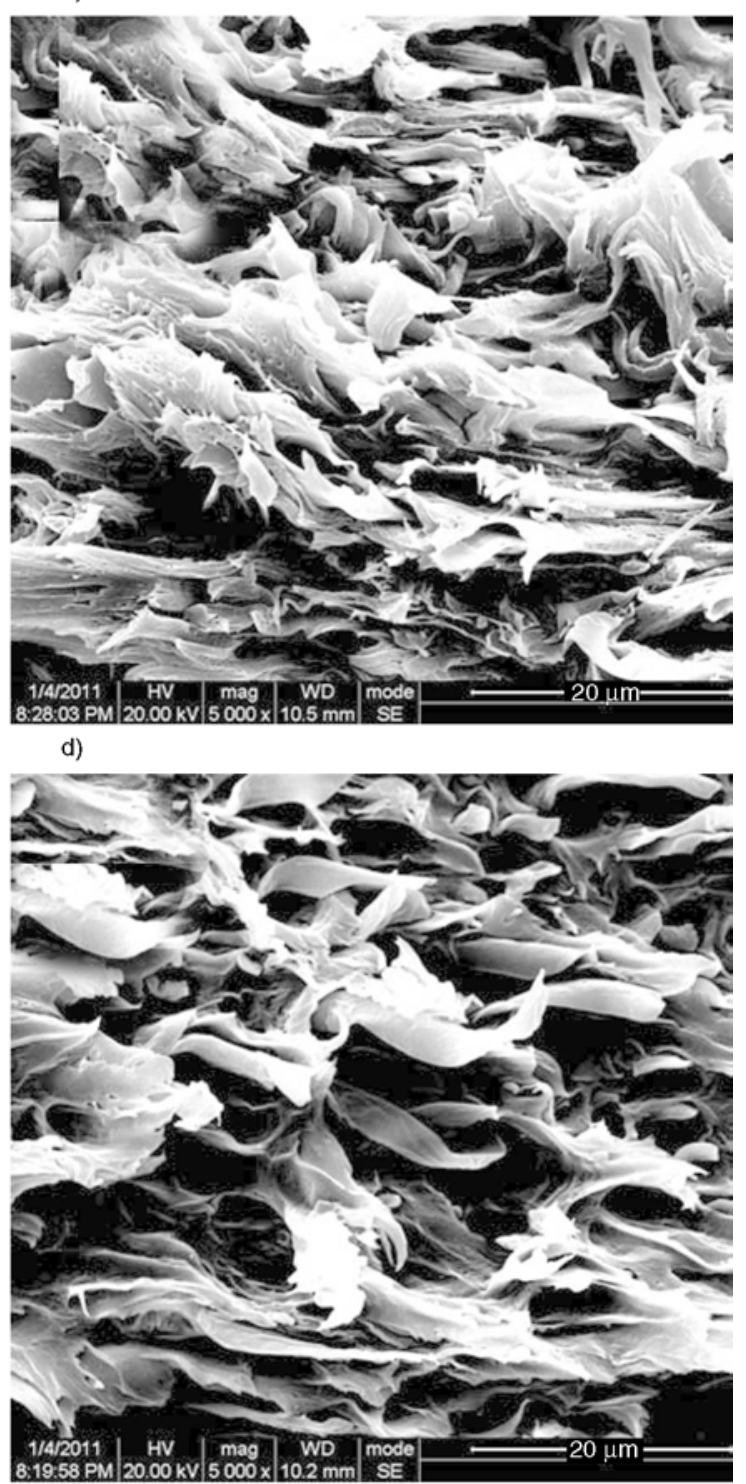

f)

Figure 9. SEM micrographs of tensile-fractured surfaces of PPC/PLA blends with and without PVAc: (a) 70PPC/30PLA, (b) 70PPC/30PLA/10PVAc, (c) 50PPC/50PLA, (d) 50PPC/50PLA/10PVAc, (e) 30PPC/70PLA, and (f) 30PPC/ 70PLA/10PVAc 
Table 2. Mechanical properties of PPC/PLA blends (70/30) with (2-10 wt \%) and without PVAc

\begin{tabular}{|l|c|c|c|}
\hline \multicolumn{1}{|c|}{ Samples } & $\begin{array}{c}\text { Tensile } \\
\text { strength } \\
{[\mathrm{MPa}]}\end{array}$ & $\begin{array}{c}\text { Young's } \\
\text { modulus } \\
{[\mathbf{M P a}]}\end{array}$ & $\begin{array}{c}\text { Elongation } \\
\text { at break } \\
{[\%]}\end{array}$ \\
\hline $70 \mathrm{PPC} / 30 \mathrm{PLA}$ & $17.3 \pm 1.5$ & $1104 \pm 80$ & $118 \pm 35$ \\
\hline $70 \mathrm{PPC} / 30 \mathrm{PLA} / 2 \mathrm{PVAc}$ & $21.5 \pm 3.0$ & $1206 \pm 100$ & $130 \pm 55$ \\
\hline $70 \mathrm{PPC} / 30 \mathrm{PLA} / 5 \mathrm{PVAc}$ & $28.0 \pm 1.0$ & $1388 \pm 130$ & $196 \pm 65$ \\
\hline $70 \mathrm{PPC} / 30 \mathrm{PLA} / 10 \mathrm{PVAc}$ & $28.5 \pm 3.0$ & $1434 \pm 150$ & $187 \pm 60$ \\
\hline
\end{tabular}

in the PPC/PLA blends, the enhancement in the mechanical properties is expected because of the significant improvement in the phase dispersion. Figure 8 shows the stress-strain curves of PPC, PLA and their blends with and without PVAc. The mechanical properties are summarized in Table 2. Clearly, although the tensile strength and Young's modulus increase steadily with increasing PLA contents, PPC/PLA binary blends exhibit a relatively low ductility (the elongation at break is much lower than that of neat PPC) probably due to the weak interfacial adhesion between PPC and PLA phases. However, as expected, the evident enhancements in both the strength and the ductility are observed upon adding $10 \mathrm{wt} \%$ PVAc. For example, the tensile strength and elongation at break increase from $28.3 \mathrm{MPa}$ and $36 \%$ for $50 \mathrm{PPC} / 50 \mathrm{PLA}$ blend to $40.2 \mathrm{MPa}$ and $65 \%$ for 50PPC/50PLA/10PVAc blend, respectively. In addition, the Young's modulus of PPC/PLA/PVAc ternary blends displays a slight enhancement with respect to that of PPC/PLA binary blends. Note that, even for 70PPC/30PLA/ 10PVAc blend where PPC as the dominant component, the tensile strength and Young's modulus still remain as high as about 26.5 and $1434 \mathrm{MPa}$, respectively, which are comparable to those of widely used polypropylene (PP) [30]. Obviously, the PPC/ PLA blend modified with a small amount of PVAc exhibits a potential to be used as a sustainable alternative to petroleum-based polymers.

In order to clarify the fracture mechanisms responsible for the improved mechanical properties, tensile-fractured surfaces of PPC/PLA blends with and without PVAc are observed by SEM. As shown in Figure 9, PPC/PLA binary blend shows an intensive interfacial debonding between PPC and PLA phases (most of the dispersed domains are pulled out from the matrix rather than being broken), suggesting a relatively weak interfacial interaction. Moreover, the domains are as large as $20 \mu \mathrm{m}$ (Figure 9a and 9c), which leads to the large voids through interfacial debonding and subsequently not only reduce the tensile strength but also develop into cracks. In contrast, for the PPC/PLA/PVAc ternary blends, the interfacial interaction is significantly improved by the interface-localized PVAc, which is able to promote the stress transfer between the two matrix phases and prevent the initiation of cracks at the phase interface [31, 32], then highly stretched and fibrillated ligaments are formed due to the matrix shear yielding (Figure 9b, 9d, 9f). On the other hand, compared with the coarse phase morphology in the PPC/PLA binary blend, the much finer one in the PPC/PLA/PVAc ternary blend is more favorable to trigger large-scale shear yielding [33].

Based on the results presented above, it can be concluded that the improvement in the mechanical properties of PPC/PLA blends with the addition of $10 \mathrm{wt} \%$ PVAc should be mainly attributed to the remarkably improved phase dispersion and the enhanced interfacial bonding through the bridge effect of the interface-localized PVAc.

\section{Conclusions}

Homopolymer PVAc has been successfully used to improve the compatibilization of partially compatible PPC/PLA blends. During melting blending, PVAc is selectively dispersed at the interface between the two matrix phases and in the PLA phase. The interface-localized PVAc acts as not only a compatibilizer to improve the phase morphology remarkably but also as a bridge to enhance the interfacial bonding, which are mainly responsible for the significant increase in the mechanical properties.

\section{Acknowledgements}

We would like to express our sincere thanks to Changchun Institute of Applied Chemistry for kindly providing the PPC, and the National Natural Science Foundation of China for financial support $(21034005,51121001)$.

\section{References}

[1] Sugimoto H., Inoue S.: Recent progress in the synthesis of polymers based on carbon dioxide. Pure and Applied Chemistry, 78, 1823-1834 (2006). DOI: $10.1351 / \mathrm{pac} 200678101823$

[2] Tan C-S., Hsu T-J.: Alternating copolymerization of carbon dioxide and propylene oxide with a rare-earthmetal coordination catalyst. Macromolecules, 30, 31473150 (1997). DOI: $10.1021 / \mathrm{ma961725j}$ 
[3] Lu X-B., Shi L., Wang Y-M., Zhang R., Zhang Y-J., Peng X-J., Zhang Z-C., Li B.: Design of highly active binary catalyst systems for $\mathrm{CO}_{2}$ /epoxide copolymerization: Polymer selectivity, enantioselectivity, and stereochemistry control. Journal of the American Chemical Society, 128, 1664-1674 (2006).

DOI: $10.1021 / \mathrm{ja} 0563830$

[4] Chisholm M. H., Navarro-Llobet D., Zhou Z.: Poly (propylene carbonate). 1. More about poly(propylene carbonate) formed from the copolymerization of propylene oxide and carbon dioxide employing a zinc glutarate catalyst. Macromolecules, 35, 6494-6504 (2002). DOI: 10.1021/ma020348+

[5] Qin Y. S., Chen L. J., Wang X. H., Zhao X. J., Wang F. S.: Enhanced mechanical performance of poly(propylene carbonate) via hydrogen bonding interaction with o-lauroyl chitosan. Carbohydrate Polymers, 84, 329334 (2011).

DOI: $10.1016 /$ j.carbpol.2010.11.045

[6] Yu T., Zhou Y., Zhao Y., Liu K., Chen E., Wang D., Wang F.: Hydrogen-bonded thermostable liquid crystalline complex formed by biodegradable polymer and amphiphilic molecules. Macromolecules, 41, 31753180 (2008).

DOI: $10.1021 / \mathrm{ma} 7020562$

[7] Yang D. Z., Hu P.: Miscibility, crystallization, and mechanical properties of poly(3-hydroxybutyrate) and poly(propylene carbonate) biodegradable blends. Journal of Applied Polymer Science, 109, 1635-1642 (2008).

DOI: $10.1002 / a p p .28002$

[8] Pang M. Z., Qiao J. J., Jiao J., Wang S. J., Xiao M., Meng Y. Z.: Miscibility and properties of completely biodegradable blends of poly(propylene carbonate) and poly(butylene succinate). Journal of Applied Polymer Science, 107, 2854-2860 (2008).

DOI: $10.1002 / a p p .27252$

[9] Jiao J., Wang S. J., Xiao M., Xu Y., Meng Y. Z.: Processability, property, and morphology of biodegradable blends of poly(propylene carbonate) and poly (ethylene-co-vinyl alcohol). Polymer Engineering and Science, 47, 174-180 (2007).

DOI: 10.1002/pen.20694

[10] Ma X., Chang P. R., Yu J., Wang N.: Preparation and properties of biodegradable poly(propylene carbonate)/ thermoplastic dried starch composites. Carbohydrate Polymers, 71, 229-234 (2008).

DOI: $10.1016 /$ j.carbpol.2007.05.033

[11] Chen B-K., Shen C-H., Chen S-C., Chen A. F.: Ductile PLA modified with methacryloyloxyalkyl isocyanate improves mechanical properties. Polymer, 51, 46674672 (2010).

DOI: 10.1016/j.polymer.2010.08.028

[12] Hashima K., Nishitsuji S., Inoue T.: Structure-properties of super-tough PLA alloy with excellent heat resistance. Polymer, 51, 3934-3939 (2010).

DOI: $10.1016 /$ j.polymer.2010.06.045
[13] Huang Y., Wang J., Liao B., Chen M., Cong G.: Epoxy resins toughened by poly(propylene carbonate). Journal of Applied Polymer Science, 64, 2457-2465 (1997). DOI: 10.1002/(SICI)1097-4628(19970620)64:12<2457 $\because$ AID-APP20>3.0.CO;2-X

[14] Liu Z. H., Maréchal P., Jérôme R.: Blends of poly (vinylidene fluoride) with polyamide 6: Interfacial adhesion, morphology and mechanical properties. Polymer, 39, 1779-1785 (1998).

DOI: $10.1016 / \mathrm{S} 0032-3861(97) 00222-\mathrm{X}$

[15] Liu H., Song W., Chen F., Guo L., Zhang J.: Interaction of microstructure and interfacial adhesion on impact performance of polylactide (PLA) ternary blends. Macromolecules, 44, 1513-1522 (2011).

DOI: $10.1021 / \mathrm{ma} 1026934$

[16] Cigana P., Favis B. D., Albert C., Vu-Khanh T.: Morphology-interface-property relationships in polystyrene/ethylene-propylene rubber blends. 1. Influence of triblock copolymer interfacial modifiers. Macromolecules, 30, 4163-4169 (1997).

DOI: $10.1021 / \mathrm{ma960995z}$

[17] Cao Y., Zhang J., Feng J., Wu P.: Compatibilization of immiscible polymer blends using graphene oxide sheets. ACS Nano, 5, 5920-5927 (2011). DOI: $10.1021 / \mathrm{nn} 201717 \mathrm{a}$

[18] Ma X., Yu J., Wang N.: Compatibility characterization of poly(lactic acid)/poly(propylene carbonate) blends. Journal of Polymer Science Part B: Polymer Physics, 44, 94-101 (2006). DOI: $10.1002 /$ polb.20669

[19] Chun S. B., Han C. D.: Morphology of model A/B/(Cblock-D) ternary blends and compatibilization of two immiscible homopolymers A and B with a C-block-D copolymer. Macromolecules, 33, 3409-3424 (2000). DOI: $10.1021 / \mathrm{ma9918708}$

[20] Feng H., Ye C., Tian J., Feng Z., Huang B.: Compatibilization effect of graft copolymer on immiscible polymer blends: 1. LLDPE/SBS/LLDPE- $g$-PS systems. Polymer, 39, 1787-1792 (1998). DOI: $10.1016 / \mathrm{S} 0032-3861(97) 00269-3$

[21] Zhang W., Fu B. X., Seo Y., Schrag E., Hsiao B., Mather P. T., Yang N-L., Xu D., Ade H., Rafailovich M., Sokolov J.: Effect of methyl methacrylate/polyhedral oligomeric silsesquioxane random copolymers in compatibilization of polystyrene and poly(methyl methacrylate) blends. Macromolecules, 35, 80298038 (2002).

DOI: $10.1021 / \mathrm{ma} 020725 \mathrm{i}$

[22] Moussaif N., Jérôme R.: Compatibilization of immiscible polymer blends (PV/PVDF) by the addition of a third polymer (PMMA): Analysis of phase morphology and mechanical properties. Polymer, 40, 39193932 (1999).

DOI: $10.1016 / \mathrm{S} 0032-3861(98) 00620-\mathrm{X}$ 
[23] Göldel A., Kasaliwal G., Pötschke P.: Selective localization and migration of multiwalled carbon nanotubes in blends of polycarbonate and poly(styrene-acrylonitrile). Macromolecular Rapid Communications, 30, 423-429 (2009).

DOI: $10.1002 /$ marc. 200800549

[24] Wu D., Lin D., Zhang J., Zhou W., Zhang M., Zhang Y., Wang D., Lin B.: Selective localization of nanofillers: Effect on morphology and crystallization of PLA/PCL blends. Macromolecular Chemistry and Physics, 212, 613-626 (2011). DOI: $10.1002 / \mathrm{macp} .201000579$

[25] Li Y., Shimizu H.: Compatibilization by homopolymer: Significant improvements in the modulus and tensile strength of PPC/PMMA blends by the addition of a small amount of PVAc. ACS Applied Materials and Interfaces, 1, 1650-1655 (2009).

DOI: $10.1021 / \mathrm{am} 900314 \mathrm{k}$

[26] Gajria A. M., Davé V., Gross R. A., McCarthy S. P.: Miscibility and biodegradability of blends of poly(lactic acid) and poly(vinyl acetate). Polymer, 37, 437444 (1996).

DOI: 10.1016/0032-3861(96)82913-2

[27] Chen B., Li X., Xu S., Tang T., Zhou B., Huang B.: Compatibilization effects of block copolymers in high density polyethylene/syndiotactic polystyrene blends. Polymer, 43, 953-961 (2002).

DOI: $10.1016 / \mathrm{S} 0032-3861(01) 00660-7$

[28] El-Hadi A. M.: Effect of processing conditions on the development of morphological features of banded or nonbanded spherulites of poly(3-hydroxybutyrate) (PHB) and polylactic acid (PLLA) blends. Polymer Engineering and Science, 51, 2191-2202 (2011). DOI: 10.1002/pen.21991
[29] Zhang J. M., Sato H., Tsuji H., Noda I., Ozaki Y.: Differences in the $\mathrm{CH}_{3} \cdots \mathrm{O}=\mathrm{C}$ interactions among poly(Llactide), poly(L-lactide)/poly(D-lactide) stereocomplex, and poly(3-hydroxybutyrate) studied by infrared spectroscopy. Journal of Molecular Structure, 735736, 249- 257 (2005).

DOI: $10.1016 /$ j.molstruc.2004.11.033

[30] Arranz-Andrés J., Peña B., Benavente R., Pérez E., Cerrada M. L.: Influence of isotacticity and molecular weight on the properties of metallocenic isotactic polypropylene. European Polymer Journal, 43, 23572370 (2007).

DOI: $10.1016 /$ j.eurpolymj.2007.03.034

[31] Wu D., Zhang Y., Zhang M., Yu W.: Selective localization of multiwalled carbon nanotubes in poly(E-caprolactone)/polylactide blend. Biomacromolecules, 10, 417-424 (2009). DOI: $10.1021 / \mathrm{bm} 801183 \mathrm{f}$

[32] Filippone G., Dintcheva N. T., La Mantia F. P., Acierno D.: Selective localization of organoclay and effects on the morphology and mechanical properties of LDPE/PA11 blends with distributed and co-continuous morphology. Journal of Polymer Science Part B: Polymer Physics, 48, 600-609 (2010). DOI: $10.1002 /$ polb. 21928

[33] Jang B. Z., Uhlmann D. R., Sande J. B. V.: The rubber particle size dependence of crazing in polypropylene. Polymer Engineering and Science, 25, 643-651 (1985). DOI: $10.1002 /$ pen.760251011 